plans for further development to set up a School of Applied Science with three main divisions. In addition to the existing subjects of electronic engineering there will be two new subjects of control engineering and materials technology. Something of these subjects is already included in the present course, but a major step forward has been made by the creation of a new chair of materials technology. Dr. R. W. Cahn, reader in physical metallurgy at the University of Birmingham, has been appointed to the chair of materials technology. Dr. Cahn is a graduate of the University of Cambridge. After three years in the Metallurgy Division of the Atomic Energy Research Establishment at Harwell, he joined. the Department of Physical Metallurgy at the University of Birmingham in 1951, where he has held in turn the posts of lecturer, senior lecturer and reader. Dr. Cahn's research work has covered numerous aspects of the crystallography and physical properties of metals and alloys. A chair of control engineering will also be set up in due course. In the development of the new School of Applied Science with the divisions of electronic engineering, control engineering and materials technology it is intended that all technological undergraduates will spend some time in each of the three divisions. It is intended that the emphasis on electronics will remain in the early stages of the new developments. An essential feature of the new plans is to provide opportunities for further study, after the first degree, with M.Sc. courses in various aspects of electronics, control and materials.

Courtaulds, Ltd. : New Research Laboratories

Courtaulds, LTD., are to transfer the work on basic research now being carried out at Maidenhead to their new laboratories at Coventry. This will ensure closer liaison between basic and applied research staffs and will enable full advantage to be taken of the wide range of facilities available in Coventry. The transfer of staff and equipment, scheduled to begin during the summer, will be completed by the autumn of this year. It has also been decided to concentrate research on petrochemicals and plastics in a new British Celanese laboratory now being built at Spondon, and due to be completed by September. Work in these fields now undertaken in smaller existing research units at Spondon and at Putteridge Bury, near Luton, will be transferred to the new laboratory. After September 30 corre. spondence should be addressed to the Basic Polymer Research Group, A. and S.F. Laboratory, Courtaulds, Ltd., Coventry, in place of Maidenhead, and to the Research Laboratory, British Celanese, Ltd., Spondon, in place of Putteridge Bury.

\section{London and Home Counties Regional Advisory Council for Technological Education}

THE thirteenth annual report of the Regional Advisory Council for Technological Education, London and Home Counties, covers the year ended August 31, 1961, and includes a statement of evidence submitted to the Robbins Committee (Pp. 39. London: London and Home Counties Regional Advisory Council for Technological Education, 1962). A plan for the regional development of courses leading to the Diploma in Technology was prepared and published during the year, and comments have been invited from the Regional Academic Board on a draft statement of policy regarding sandwich degree courses. A regional survey of B.Sc. courses has been made. Recommendations have been made and adopted regarding the geographical distribution and demand for degree courses in chemical engineering, as well as courses for the Diploma in Technology and in Technology (Engineering). A report on education for civil and structural engineering in technical colleges in the region is being printed.

\section{Organization and Method in Local Government}

THE valuable contribution which an organization and methods unit can provide in improving the efficiency of local government services has been described by J. L. Hampshire, County Treasurer of Kent (Productivity, 1; January/February 1962. An International Journal and Abstracting Service for Industrial and Business Managers to help Increase Productivity in Factory and Office. Pp. 56. London and New York: Pergamon Press. Annual subscription, six issues, 70s.; United States and Canada, 10 dollars). In Kent the Organization and Methods Unit was installed in 1947 and, since then, has carried out investigations in many departments. These include a general reorganization of the Finance Department including the Licences Division, and a general survey of the relationships between the Finance Department and other Departments in such matters as the control of requisitions for supplies and the certification of accounts for payment. Staff members in the Finance and Licences Divisions of the Department were reduced at a time when considerable additional work was being absorbed and the financial savings were considerable. Since 1950, a large number of assignments of a varied character have been carried out. The work has at some time or other affected every County Department, and, although many of the assignments have resulted in ascertainable financial savings, there have been instances where increased effectiveness of the work has been the only aim, and savings, if any, have been of an indirect character. During 1955-56 it was decided to place emphasis on overall departmental investigations while continuing to work on purely subject assignments to meet specific needs and requests. From the beginning it was realized that savings would result from the technique involved. The aggregation of the figures shows that, up to March 31, 1961, realized savings attributable to investigations made by the Organization and Methods Unit amount to approximately $£ 75,900$ a year and that suggestions are now under consideration which may involve further savings.

\section{Royal Observatory Annals}

Most scientists are aware that fashions in publication have changed in recent decades, and that the general trend is one of publishing less and less detail. Indeed, the growing costs and volume of material that is suitable for publication have compelled many scientific journals to restrict their acceptance of tabular matter to very modest proportions. This is, in many cases, reasonable, but it has thrown a burden on workers in certain branches of astronomy. It is still necessary to make extensive catalogues and observations available to other workers. It is not, therefore, surprising that it has become necessary to start a new publication, Royal Observatory Annals, joint publications of the Royal Greenwich and Cape Observatories, published by H.M. Stationery Office (No. 1: Nutation, 1900-1959. Prepared by H.M. Nautical Almanac Office. Pp. vii + 41. London: H.M.S.O., 1961. 7s. net). No. 1, 1961, contains numerical tables of nutation in longi- 